\title{
تطبيق منهج التفكيك على رواية (نزل الظلام)
}

Applying the Deconstruction Approach

to the novel (Nozol Alzalam)

קكتوبة/ نرجسبا عبد الففار بازهير

أستاذ مساعد قسم الار اسات و العلوم الأساسية

كليه المجتمع - جامعه تبوك

المملكة العربية السعودية

تمنل فرنسا المهد الأول للتفكيك، والذي انتقل إلى أمريكا عبر رحلة قادها دريدا الذي ألقى محاضر اته في جامعة بيل وجونز هوبكنز ، هذه الأخيرة التي شهدت ميلاد المؤتمر الأول للتفكيك عام 1977 م، لتسود بذلك التفكيكية إلى الساحة النقدية الأمريكية في السبعينات، ويتأثرّ بها العديد من المؤلفين و النقاد "لتهيمن بذلك أفكار دريدا على الساحة الأدبية وخاصة على النقاد الرومنسبين و الناقمين على موجة النقد

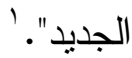

وتمثل التفكيكية جانباً مخيفاً من جو انب فوضى النقد المعاصر، حيث شبهها بعض المعارضين لها بأنها كرنفال، تخضع الحياة لقوانينها فقط و لا حياة خارج

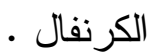

إن جوهر التفكيك كما ير اه جالك دريدا هو غياب المركز الثابت للنص، بمعنى أن التقكيكية تقوم على فلسفة التشكيك في العلاقة بين الدال و المدلول، ممايعنى أن المعنى لبس معطى جاهز ، و أنه غير حاضر في الإشارة اللغوية ( الدال ).

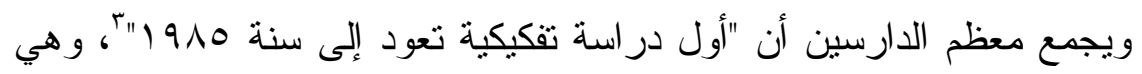

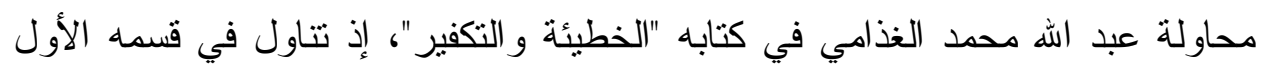


المناهج النقدية الألسنية، وشاعرية النص، ومصطلح تداخل النصوص، وما إلى ذلك من المفاهيم، في حين خصص قسمه الثاني لمقاربة قصيدة حمزة شحاتة و الموال

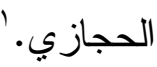

' انظر : الغذامي، عبد الله محمد : الخطيئة والتكفير من البنتوية إلى التشريحية، قراءة للأنموذج إنساني معاصر، مقدمة نظرية

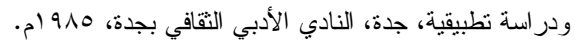




\section{تطيق المنهج التفكيكي على رواية (نزل الظلام ) للكاتب ماجد الجارد :}

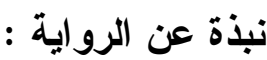

إير اهيم كان مبصر ا وفقد بصره بالتذريج كنتيجة لعامل ور اثي وبقي لديه آثار

نور ، حيث تخزن ذاكرته بعض التفاصيل وتغيب عنه أكثرها، حمله و الده إلى معهد في مكة المكرمة، ومن هنا يبدأ مشو اره مع حياته الجديدة.

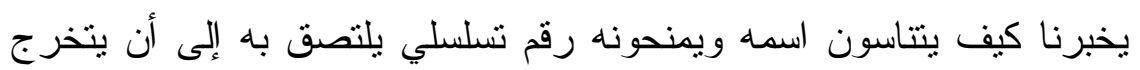

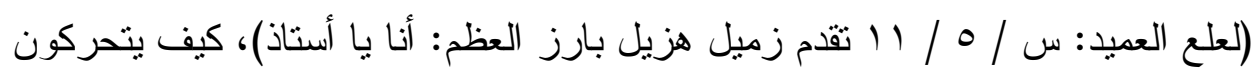
كوحدة كلية لا ر أب لها، مأمورون بالصلاة، و الأكل، و الدرس، و النوم، في مو اعيد ثابتة بغض النظر عن ما يدور في نفوسهم من شهوات بريئة.

يحملون كتب براين الثقيلة عليهم كأطفال، يرون الثمس ( أو يشعرون بهابها بهن ) عند ركوبهم الباص بين المعهد و النزل قبل أن يسجنو ابلا جرم، وتقنن خيار اتهم القليلة التي لا سبيل لديهح سو اها، فلو تزكوا النزل وتزكو ا الدر اسة لن يجدو ا وظائف تكفيهر حد الكفاف.

الرواية مؤثرة، غارقة في الإنسانية، عذبه حد الألم، فيها معاني مؤلمة جداً

تتحدث عن انعدام الخيارات، عن حياة ليس فيها إلا لونين أبيض وأسود ، نور وظلام. (نزل الظلام) .. إذا نظرنا إلى هذا العنوان منذ البداية سنشعر بإحساس القهر لهاه

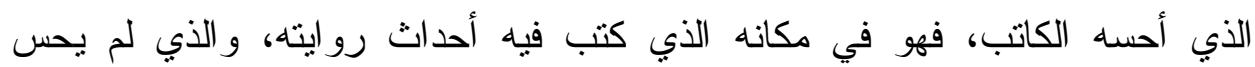
بإحساس شعاعي فيه بل أحس بأنه من ظلام إلى ظلام.

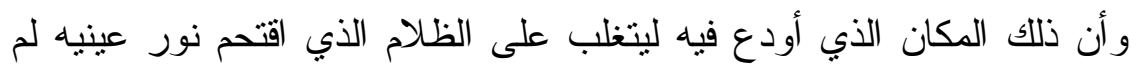
يزد حالته إلا سوءاً، ولم أثنعر أنه بذلك كان بعني الظلام من حوله و الذي تعكسه أعصاب عينيه الضعيفة، بل كان بعني الظلام الذي ينبع من إحساسه الداخلي؛ نتيجة لشيء أو عدة أثنياء حاكتها تفاصيله اليومية في ذلك المكان الذي كان سبياً في ابتعاده عن حضن الأمان، حضن و الدته وأسرته التي كان يحيا في كنفها. 
فنزل الظلام توحي بإحساس من البعد، ومحاولة التشبث بالماضي الذي يبتعد

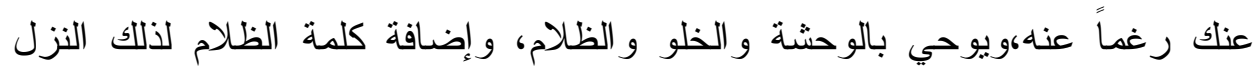
تعمق لدينا ذلك الإحساس بالغربة و الوحشة و الظلم. (تمهذني حجرها، وتسعفني صدر ها؛ لأروي عروقي من قلبها النابض أمومة،

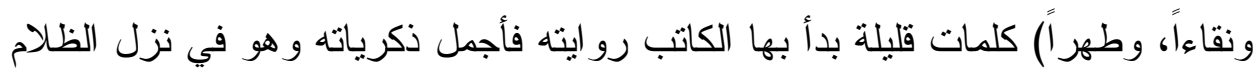
هي حضن الأمان، وكأنه يتشبث بتلك الذكريات؛ لتمنحه الدفء في ذلك النزل البارد المظلم، كل تلك الكلمات توحي بفقده لحنان أمه التي تمنل العائلة و الدفء بالنسبة له.

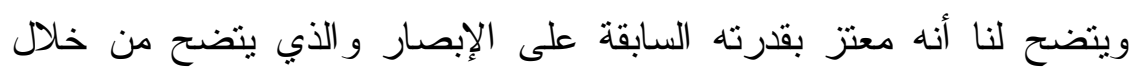
قوله:(أنهادى في الصالة، أقترب من صينية الثاي، أتلمس لمعة الفص الكريستال المزين رأس إبريق الثاي)، فحلاوته تلك المرحلة في شقاوته وملاحظته للأشياء اللامعة و الجميلة التي كانت من حوله، والمقصود من كل ذللك الوصف ليس جمال

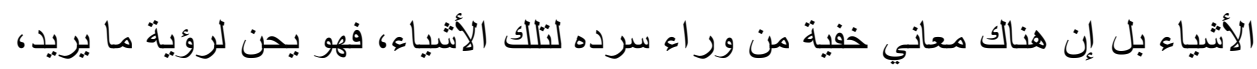

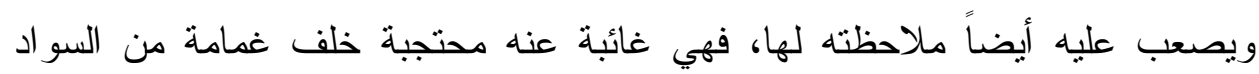
ولكنها أصبحت محيطة به ، ويتجلى ذلك بقوله : (وفي ليلة ، خيم ظلام طارئ .....) فالظلام الذي غلف البيت و الذي قام بوصفه أثنعل في قلبه الخوف، الخوف من ذللك

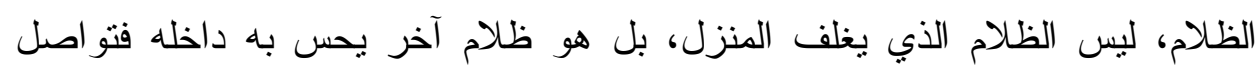
بكاءه، ولم يتوقف عن البكاء إلا عندما أشعلت أمه شعلة الضياء وأحس بها تحمله،

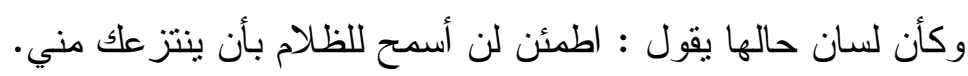
و هو يحاول بشتى الطرق أن يتمسك بقدرته على إبصار ما حوله، فنر اه يقول:

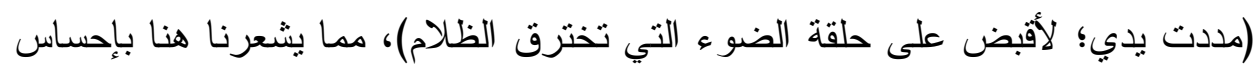

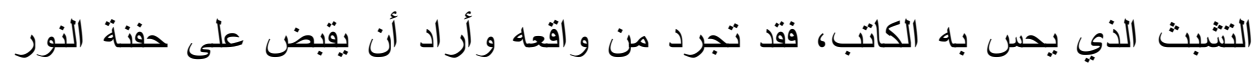
التي نتق طريق الظلام من حوله. ويتجلى ذلك التمسك بالضياء في مواقف صغيرة حدثت له أثناء خروجه مع أهله إلى التخييم، فكلما حل الظلام كان ير اقب السر اج الصغير المعلق في الخيمة وكأنه يرجوه أن لا ينطفئ، وكأنه بانطفائه تتطفئ أنوار عينيه، ذلك الظلام الذي سيحرمه من لن 
رؤية وجه و الدته المحبب إليه، فنر اه يقول : (أمضي الليل ممسكا بو جهها،و أضعه قبالة وجهي الصغير ، وأثنير إلى السر اج المعلق على عمود الخيمة). إحساس بالألم يعتصرني وأنا أحاول أن أتلمس المعاني العميقة من وراء كلماته، فهو بإطالته النظر إلى وجه ملاذه وبإثشارته إلى شعلة الضوء المعلقة في

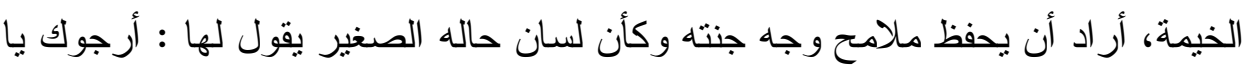
أمي لا تسمحي لضياء عيني بالانطفاء، فكأنه يحتمي بها كما تعود دائماً.

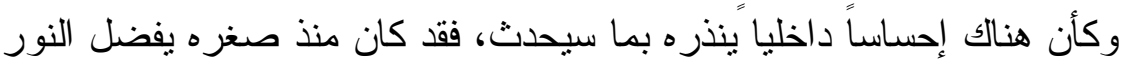
على الظلام، و الأماكن المشعة على تلاك المظلمة، فنر اه يقول : (كنت أؤثز اللعب في لهاه الأماكن المضيئة، و أتجنب العتمة...)، وفي قوله :(أخي المبصر يفضل اللعب في هذه الغرفة المترعة، أما أنا فأفضل اللعب خارج المنزل، ألهو بالرمل، أسقي الثجيرات) تللك الأمور الصغيرة التي وصفها إبر اهيم ليست إلا أمور تتصب في نبع واحد، وهو الحرمان الذي سيعيشه، تمنل له كل ما سيحرم منه وكل ما يريد أن يثبع حو اسه منه. وفي ذكره لمدى نتبه و الديه وصدمتهما بعد ذلك بحقيقة حالته إحساس بالعجر مانه

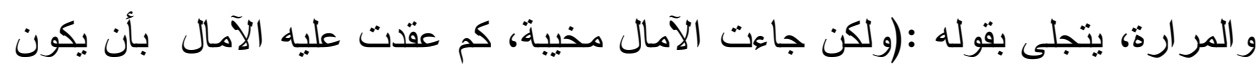

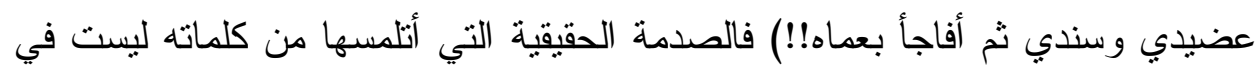
حقيقة اقتر ابه من عالم الظلام بعد أن عاش في النور، بل تكمن تلك الصدمة في (الأعمى لا يقدر على صنع شيء) عبارة استتتجها من كلمات و الده، و استشفها من يأسه و غضبه.

ثم ينتقل إلى تيقنه بحجم مصابه في قوله : ( وتحطم زورقي الصغير)، كم

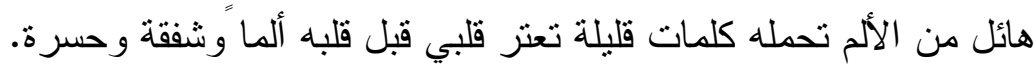

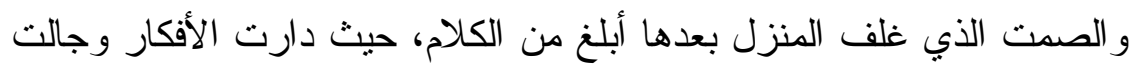
في نفس كل قاطنيه (فصمتا غارقين بدوامة عميقة). وتأتي ساعة الحسم .. فتزجوا الأم أبا إبر اهيم بأن لا يستسلم وأن بقدم على على خطوة قد تكون بداية طريق الخلاص. 
الخلاص الذي كانت تتمناه الأم على الرغم من يقينها بالعكس، حيث يتمنل ذلك

$$
\text { في قولها : ( سيزول بنظارة بسيطة أو قطر ات يسيرة). }
$$

فهي تعلم أن تلك الحلول لن تأني بنتيجة ملموسة في حالة ابنها، ومن وراء

تلك الكلمات نستشف كمية الهلع و اليأس الذي وصلت إليه الأم.

و على لسان الأم كتب الكاتب (بذلت جهدي ليزورنا أطفال الجيران فابتكرت

المغريات، من دمي ...) ، فأم إير اهيم بشخصيتها العطوفة و إحساسها بما يعانيه ابنها،

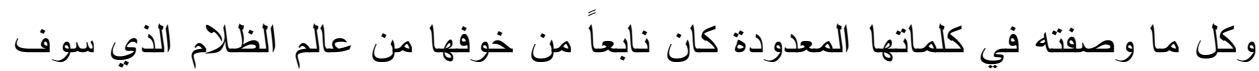
تعيشه قطعة من قلبها في الأيام المقبلة.

و الأب بشخصيته المتماسكة كان في داخله يحترق ( كلمات أمي ألهبت مكامن الأبوة، فغدا كالملدوغ يبحث عن طبيب ينتزع من قلبه الألم)، فكأنه هو من يعاني، و هو

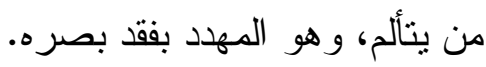
يحاول إير اهيم ملاحظة كل شيء و النظر إلى أدق تفاصيل الأثياء من حوله، فهو في عيادة الطبيب يحلل الطبيب، و المكتب أمامه، وأدق التفاصيل التي تغلف ذلك إنك

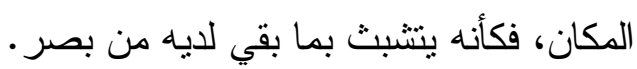

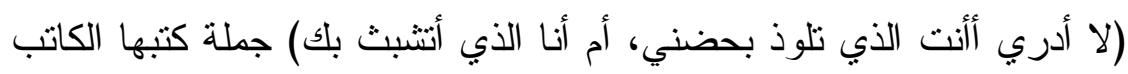

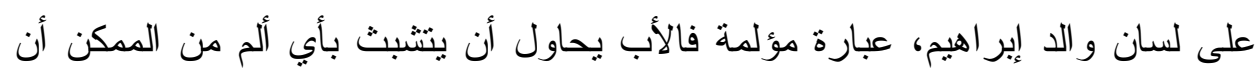

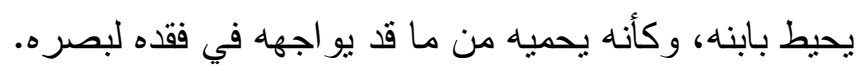
(وأحايين تسمح بظهور قرص فضي منير، ليس كالثمس إنما هو نور بلا توهج، ينأى بعيدا أو يحتجب بين الغيوم)، كلمات قليلة تقريرية في ظاهرة تخفي ور ائها

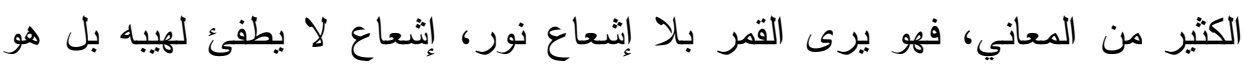

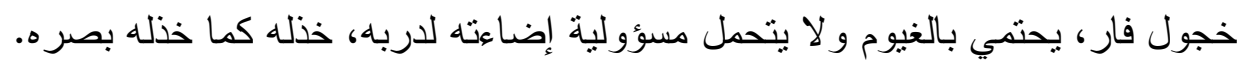

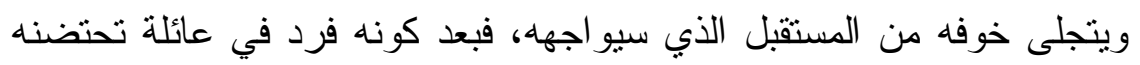
وتلبي كل رغباته أصبح رقما تقدم له وجباته في أوقات مفروضة عليه (وليت القائمين على السكن نساء فتلجئني أمي إلى غريزة الأمومة لديهن...)، فكأنه يحس بأن أمه 


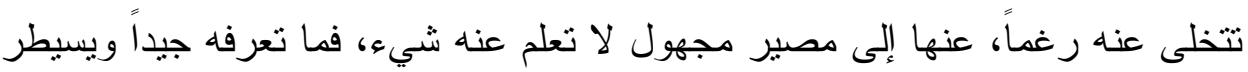
عليها أنه لا مكان له بينهم.

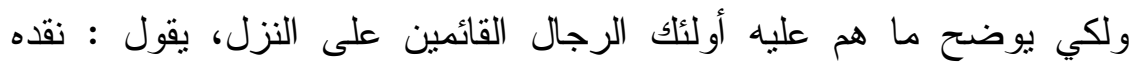

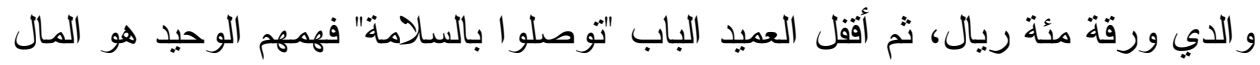
و لا شيء غبر المال، وكأنه أر اد أن يثبت هذه الحقيقة بقوله هذا.

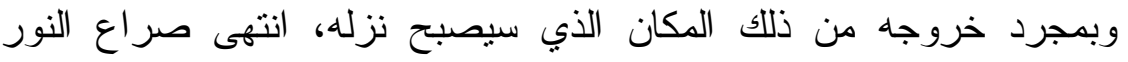

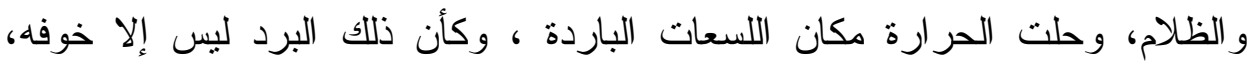
و الصر اع لم يكن إلا بين ماضيه الجميل ومستقبله المجهول. وفي أول أيامه في النزل كان و الده بجانبه كالبد التي تسنده وتمده بالتوازن

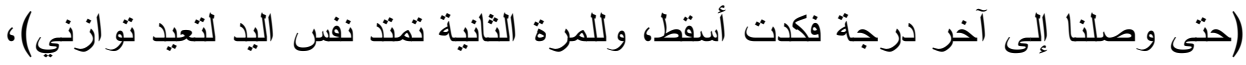

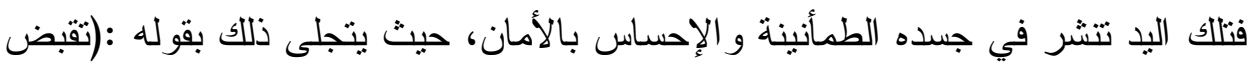
على كتفي)، وفي قوله "(للمرة الثانية)، يصلني إحساس بأنه مهما جنب الطريق ومهما و اجهته مصاعب فإن و الده سيكون بجو اره كالدر ع الذب يسنده ويحميه ويدافع عنه. وفي قوله: (بعدها ننظظم عند الحمام، ونفرش أسنانا إجباري ثم إلى الفراش

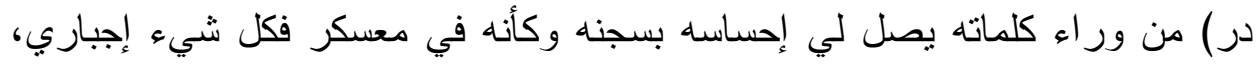

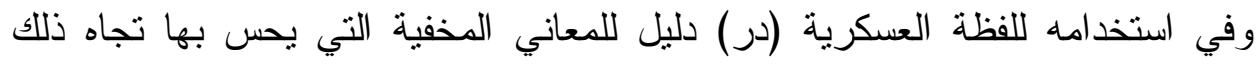

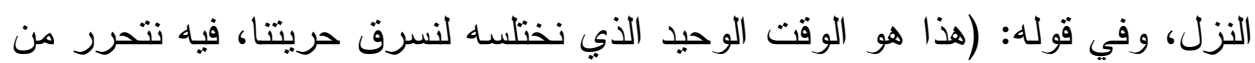

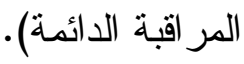
وهو لا يجد راحته إلا في مكان واحد في ذلك المكان (و أما النربية الفنبة حين

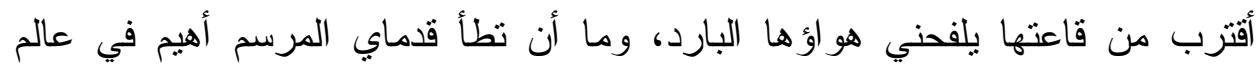

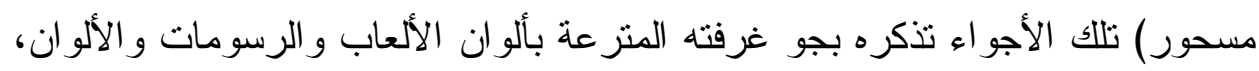
ولهذا عدها المكان الذي يجره إلى عالم مسحور أي إلى غرفته الصغيرة في كنف أهله، وهي أيضاً الثيء الوحيد الذي يتقن عمله فيفردها ويطويها ويعبث بها. النها. وأحس باستسلام إبر اهيم الذي ينجلى بقوله : (عندها اكتثفت أنه عصير التفاح الذي لا أحبه لكني تجر عنه). 
فهذا المكان الأشبه بالسجن له أثاث قديم (أخطأته فدوى دولاب الملابس

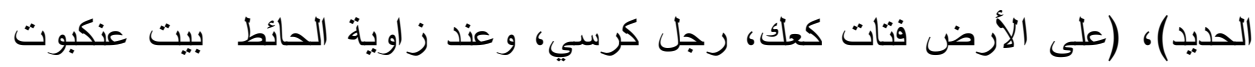
قذر) يصلني من وراء تللك الكلمات القليلة ما كان عليه ذلك النزل من قلة ونلة نظافة ور عاية صحية.

و الطلاب فيه لا يأخذون من حقهم إلا القليل وكأنه بقوله: (وكأنهم نمل يتجه ليحمل فتات المو ائد) يريد أن يوصل لنا حقيقة صرف الميز انية المخصصة لهم، فهم لا لانهان يأكلون كما يأكل المسؤولون عنهم، وليس لهم من الأثاث ما لدى رؤسائهم ، وقد تجلى بلى لئل ذلك في وصفه لمكتب المدير • بالكون وفي قوله : (ويشرف عليهم عميدان وفر اشان يز هون ببطون ومؤخرات كبار)

تحقيق لتلك الفكرة الكلية التي يريد إيصالها لنا من خلاص كلماته. و إن ما يصبر خالا على ذلك الظلام و الأسوار هم أصدقاءه خالد ومحمد فهو لأهو ثالث لهما لا يفترقان، محمد القروي الذي يتوق إلى قريته التي يعدها بلا وجود على

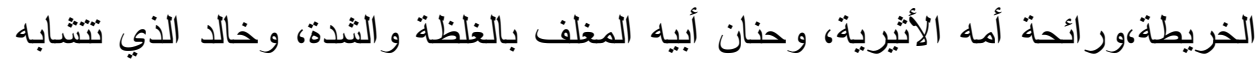
ظروفه مع ظروف إير اهيم فيزور أهله كلما سمحت الفرصة لذلك، فهو من سكان عروس البحر الأحمر وأقربهم إلى النزل. فئ. وفي انتقالهم إلى مرحلة عمرية جديدة انتقلو إلى سجن أكبر (النورية) يتلاءم مع سنهم أكثر، فكلما تقدمو ا في العمر كلما ازداد الظلام و أحكم السجن قضبانه. اسم هذا النزل مناقض تماما لما عليه حالهم، وكأنه يغيظه في كل مرة ونه ينطقون به أو يسمعونه. لقد كان النزل الأول (ريع الكحل) موحشاً، ولكن له ثغرات تشمح للنور بالاخول، فهناك الباص الأصفر، وبقالة العم دويخل الذي كان يشفق عليهم ويتغاضى عن نزواتهم، وهناك بائع الآيسكريم و الخضار و البسبوسة، والحارة التي تطل عليها

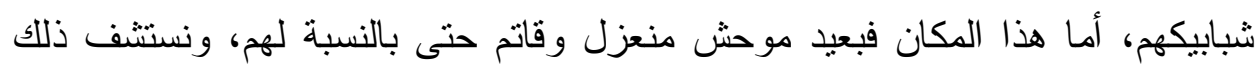
كله من قوله : (وحين ننفرد بفرشنا في الليل وخاصة ليل الثتاء الطويل، يعلو صر اخ 
الريح ،ويجول بين الردهات المققرة نباح الكلاب الثناردة، ويفزعنا هدير السيارات

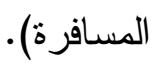

توصل لي تلاك الفكرة بعض وصوفه لذلك المكان فهو بقوله: (إنه هناك تحت ذلك الجبل الثاهق) فكأنه يثير إلى المجهول الذي ينتظرهم و الذي سوف يشهر عليه

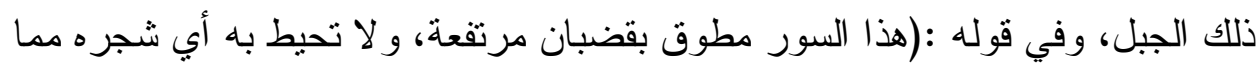

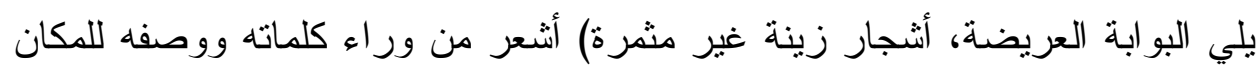

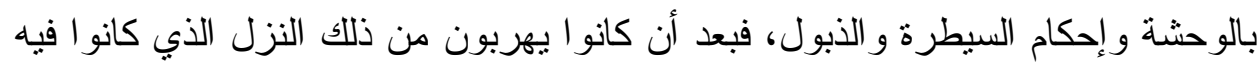

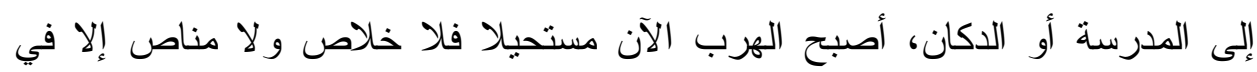
نهاية الأسبوع، وليس كل من هنالك بسعد بتنلك اللحظات أيضاً. وفي وصفه للعب ذللك النزل حين يقول : (أبضض نلاك الملاعب التي تحنوي

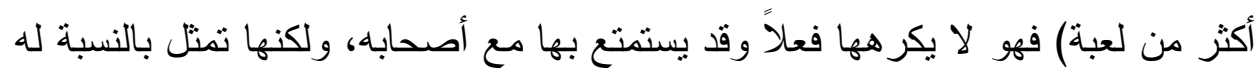

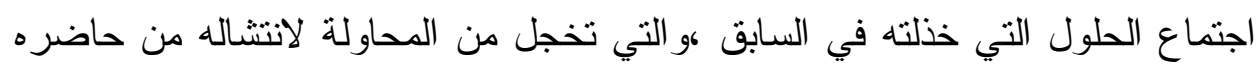

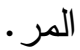

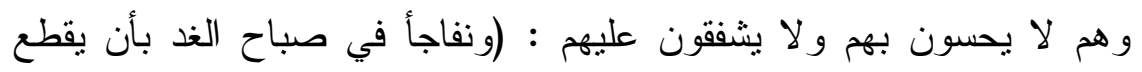
المعلم المبصر الدرس؛ ليدلق نكاته الباردة حول البقع التي لم يصل لها الدعك الجيد، أو لو

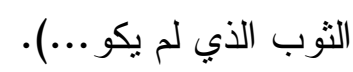
(أما الكرة قد أحضرتها من بيتي ، وأما العمداء نعلن عليهم العصيان!!) من هذه الجملة بدأت ثورة الطلاب على ذلك المكان، وعلى ظلم العمداء، وقلة موارد الأكل، وتهميش الرغبات البسيطة و الطبيعية لهم.

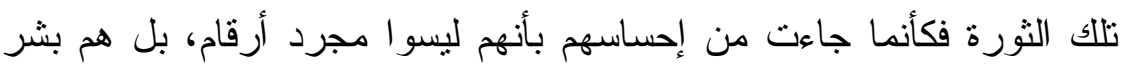

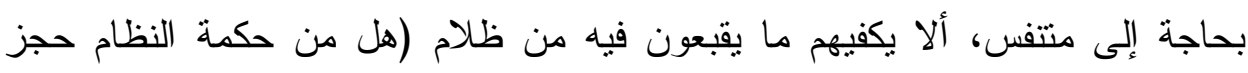

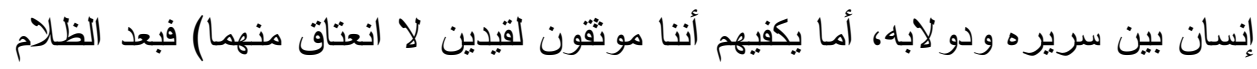
الذي يغلف حياتهم، وذلك النزل الثرهملم يتبقى إلا الحجر و الحظر الذي يفرض عليه لئهم ويمنعهم من مز اولة كل ما يحبون ويشتهون. 
وفي قوله : ( فهو يطبق على المغفلين و لا يحميهم) وكأنه بنلك الكلمات يستثير همة زملاءه ليتحالفو ا معه، فلا عصبان بلا تكاتف وتعاون. بدأ الأطفال يكبرون، وبدأت الحياة تعلمهم، وأول درس فيها يتضح بقوله بـانه: (... لماذا لا يدرسونا حقوقنا؟، وحدود صلاحيات العمبد).

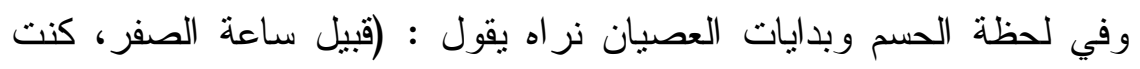
أنأمل حزمة ضوء تعبر بين قضبان شباك قاعة الطعام) فهذا ضياء الحرية و التمرد الذي يطالبون من خلاله بحقوقه، فما هذا الضياء إلا بقعة ضوء في في أرضهم المظلمة، فئه

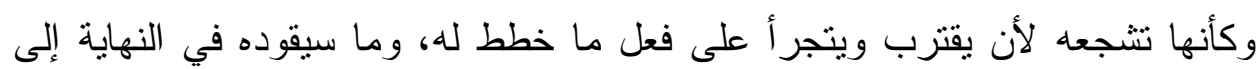
مطلبه ومر اده و أبسط حقوقه.

وجاءت ساعة الانتصار وكأن الكره هي ملاذه، وهي ما يحتمي بها (تركنا

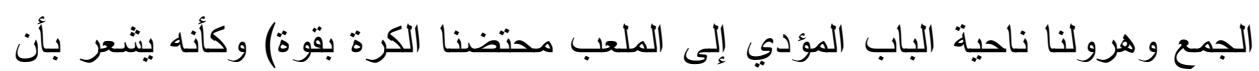
تلك الكرة حلمه بالحرية، ولو سقطت لسقط الحلم وتبددت الحرية.

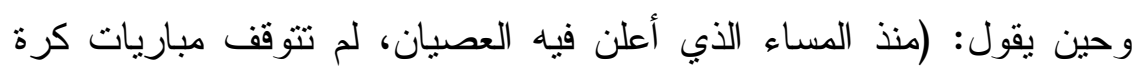
القدم، ... لكن حين يهبط الظلام تستيقظ نزعة التسلط لدى العمداء) نشعر بالمعنى الخفي وراء تلك الكلمات فحين يحل الظلام يتسلط المبصرون فهم الأقوى، ومن كان

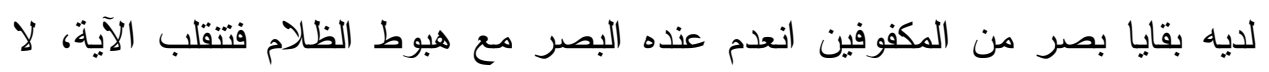

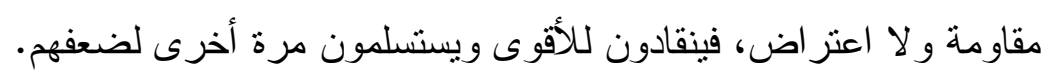
و ها هي تتحقق ثاني نتيجة لصوت عصيانهم، فبعد اللعب لا بد من سد الجوع ورمق العطش ( في الغد ... ينبعث من تحت أحد السلالم غناء وتصفير، ونشر وقطع، لهن وطرق وخرم) فها هو صوت الاتتصار متمنل بصفير العم سيد، وها هي بشائر الانتصار تزفها لهم أصوات نشر فور الخشب. ومع كل حركة بناء تبنى في أحلامهم تفاصيل الحلم ( لم تتوقف أذهانتا عن البناء، حتى انتهت معزوفة سيد المنجرية، عندها تلمست أيدينا الو اقع). 
وفي قوله : (و انتصبت ثلاجة مرطبات، تمدد سرير هناك في أقصى زاوية

تحت سقف الدرج، وجلس دولاب صغير)، هذه تفاصيل الحلم، فليس الأكل ورلا المرطبات بحد ذاتها هي المطلب، بل تتفيذ الرغبات وبصيص الأل الأمل.

ولكن تصلنا فكرة من خلال قوله : (تمدد سرير هناك في أقصى زاوية تحت

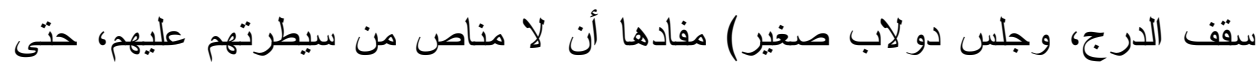
و إن قامو ا بتتفيذ بعض مطالبهم لهم وتتفيذها.

وبذلك يتحقق لهم الهدف الثالث من أهداف مطالباتهم، فها هو يحل عليهم يوم

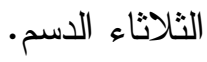

وها هو الهدف الر ابع بلوح عندما أنشأو ا موجتهم الخاصة بهم (دولة العميان)،

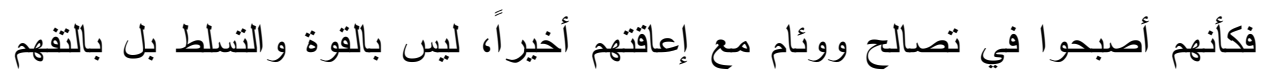

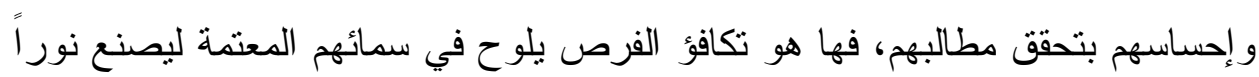
من نوع خاص، نور من صنع أيديهم يزيد من تحقيقهم لذاتهم.

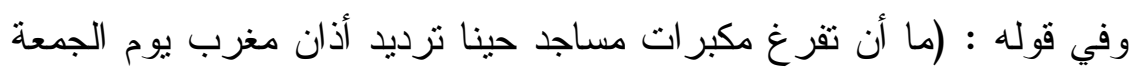

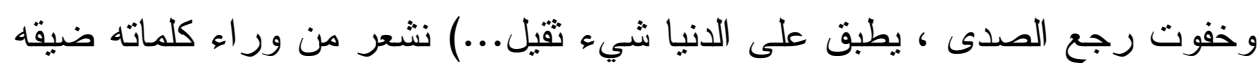

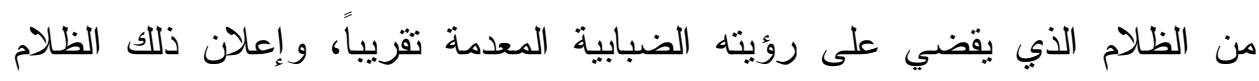

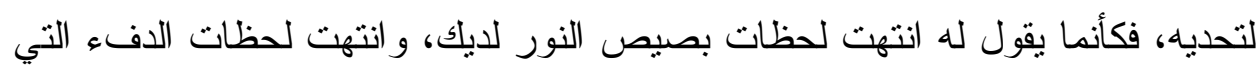

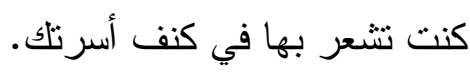
ويتعمق لديه إحساس الغربة في قوله :(أغرق يدي في حوض سمك الزينة، كم هو محظوظ ! على الرغم من حبسه يعيش داخل الماء وبين شعب المرجان، في بيئة

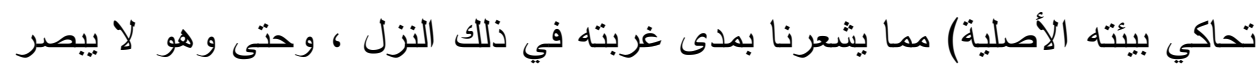

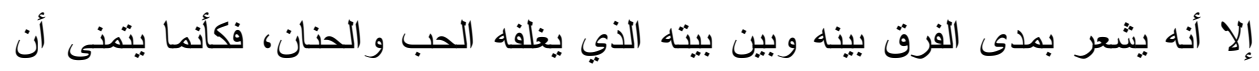

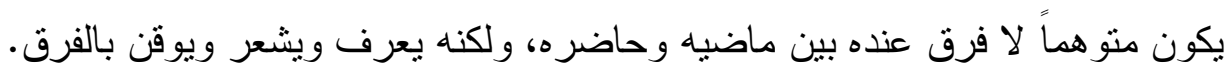

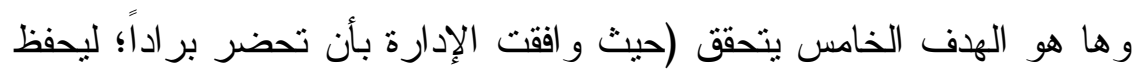
به ما تبقى من الوجبات ، كالخبز ...). 
وفي قوله: (نحن رهبان النزل الثلاثة اكتسبنا مهارة في تدبير أمورنا ، وكسر

الأنظمة...) وقوله أيضاً: (نشترك لنشتري قنينة الكاتشب ...فيضاف على إدام الخضار

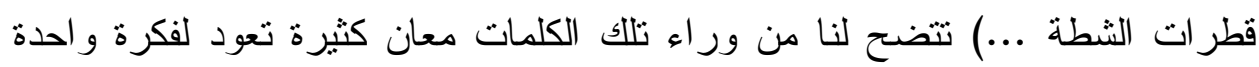
وهي كسر هم لقيود ظلامهم ومصالحتهم معه. وأثنار في قوله : ( أمضينا اللبلة ننسج أحلاماً في ما سيعرضه وله التلفزيون المجسم. سأتتبع بيدي حركات لاعبي الكار اتيه الصينيين وهم بتقافزون برشاقة ...) أن فئن الأحلام تكبر و التصالح مع الإعاقة تظهر تباتنيره وتلوح في الأفق ، فبعد أن كان النزل

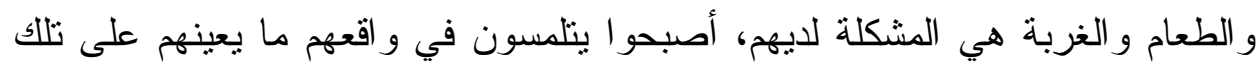
الغربة وذللك الإحساس بالفقد والنقص، وها هم يتكاتفون ليدلي كل فرد منهم بما يبرع به : (اسمعو ا يا شباب اسمعوا صوت في الطرف الآخر ، شغل عيونك يا خالد شوي لهاب بس، ضع يدك فوق حاجبيك)، (محمد خليك من جهة السيار ات المقبلة حتى تسمع جيداً،

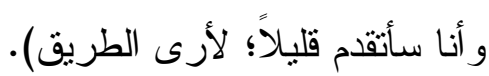

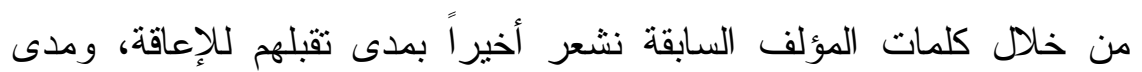
شجاعتهم وتعاونهم؛ لاعتمادهم على أنفسهم في مواجهة ظروف الحياة، فكأنما الثارع

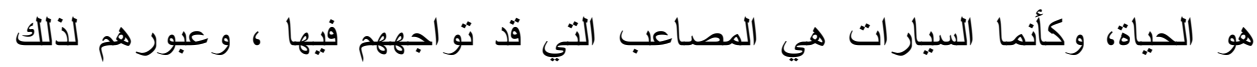
الثار ع كعبور هم للحياة، وشجاعتهم لمواجهة السيار ات هي استعداد تام منهم لمواجهة

$$
\text { أي مصاعب قد تواجهـم فيها. }
$$

وفي النهاية أجد أن من أجمل ما شدني في هذه الرواية هو طريقة الكاتب،

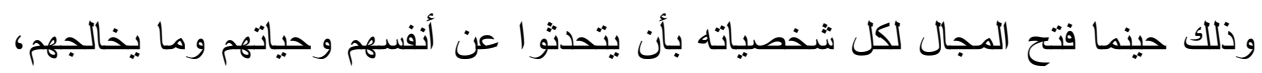

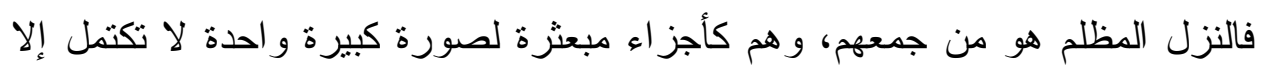
بوجود ثلأك الأجز اء و اجتماعها معاً. 


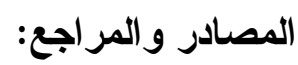

سيلدن، رامان: النظرية الأدبية المعاصرة، نرجمة سعيد الغانمي، المغرب، دار فارس،

$$
\text { . } 1997
$$

يوسف و غليسي: التفكيكية في الخطاب النقدي المعاصر، مجلة القوافل السعودية،

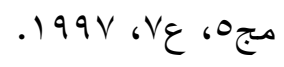

ht t p://el bouramrani .bl ogvi e.com

الغذامي،عبد الله محمد: الخطيئة والتكفير من البنيوية إلى التشريحية، قر اءة للأنموذج إنساني معاصر ، مقدمة نظرية ودر اسة تطبيقية، جدة، النادي الأدبي الثقافي، 910 ام. 
